to be influenced by the old anatomical evidence from the completely fern-like structure of the Psaronius stems and roots. If Psaronius belonged to seed-plants, comparative anatomy would be discredited. Yet it has proved its value, for it was anatomical data which first put us on the track of the Pteridosperms, before the seeds were discovered.

The question of the evolutionary relations of the Pteridosperms, whether they were "ferns which had become Spermophytes" or an independent line of descent, cannot be settled until we know whether the tree-ferns of the Carboniferous were ferns indeed or seed-plants simulating them. A seed-bearing Psaronius would go far to resuscitate the former hypothesis, which of late years has seemed the less probable of the two. No such case, however, is as yet demonstrated. The whole question is in urgent need of further investigation.

\title{
Geometrical Art in South-east Europe and Western Asia.
}

\section{By Prof. John L. Myres.}

$\mathrm{B}$ ETWEEN the vivid naturalism of Minoan art, the mature style of Crete and the South Egean in the later Bronze Age, and the serene idealism of Hellenic art, in the great centuries from the sixth to the third, intervenes a style profoundly contrasted with both, popularly known as the Geometric Style of the Early Iron Age. It inherited something from Minoan art, and contributed more than appears at first sight to Hellenic ; but in its maturity it was the negation of all that either Minoan or Hellenic craftsmen aspired to express. Such a group of facts, or sequence of events, presents a problem as fully worthy of scientific treatment as any crisis in geology or natural history: the problem, namely, of the apparitions and disappearances of geometrical art in the lands around the Greek archipelago. For the geometrical art of the Early Iron Age was not the only such occurrence; and its significance is best appreciated by comparison with other geometrical styles.

What we call style is approximation to a standard of achievement ; and perfection of style is beauty in art. Geometrical styles come into being in various ways. In primitive Crete, as in other parts of the Mediterranean, vessels of clay were decorated with ornaments which were linear because incised, and rectilinear because they imitated basketry. Such skeuomorphic ornament is not 'geometrical' so long as its imitative intent is obvious ; it becomes so as this intent is superseded by appreciation of the linear designs as pure forms and spatial constructions. Before this stage was reached in Early Minoan art, these linear designs were superseded by more or less naturalistic representations of plants and animals, scarcely restricted at all except by the surface of the decorated object.

Similarly, the painted pottery of Thessaly, probably derivative from a widespread Ukrainian culture between Danube and Dnieper, is decorated with lines and bands the prototypes of whichtextiles or leatherwork-are uncertain, but the application of which, with utter disregard of the forms of the vessels, is the antithesis of early Egean 'skeuomorphs.' This primitive style also perished early (with one possible exception) in conflict with the paintless 'gray-ware' of Orchomenus, and the almost paintless 'smear-wares' (Urfirniss) of the Greek mainland.

' Summary of a discourse at the Royal Institution on Friday, Feb. 1.
East of the Egean, in the heart of Asia Minor, another painted linear style, still imperfectly known, influenced Syria and Cyprus late in the Bronze Age. It may be connected either with the Ukrainian culture or with that of Susa and other sites in the Persian hills and early Babylonia. It does not, however, seem to have affected the coast. cultures of the Egean until the Early Iron Age, and even then but slightly.

After great naturalistic achievements, Minoan ornament declined into mechanical and conventional abbreviations, and broke up into numerous local schools, during the troubled centuries from 1400 B.c. to 1100 B.C. or later; and it is as the sequel to this artistic collapse that the Greek geometrical style comes into being. It has been commonly supposed that the new style was introduced into Greek lands by ' northern invaders' from beyond the Danube, or at all events from Danubian countries. But recent discoveries, especially in Macedonia, have shown that, though an invasion occurred about 1100 B.c., its range was restricted, its effects were transitory, and the culture it introduced temporarily had no geometrical elements, other than a fondness for compass-drawn concentric circles, which had a fairly wide vogue in the mature geometrical repertory of the Egean, and a far more general popularity in the contemporary art of Cyprus, where there is some reason to suppose that it arrived overland through Asia Minor from the same south-east European source. A second suggested source for the geometrical style of the Egean is in certain scattered and belated survivals akin to the primitive Thessalian decoration, which have been detected in north-western Greece : and as the 'Dorian' invaders of peninsular Greece were traditionally derived from this region, these may represent the decorative style which they had before they came south.

It is difficult, however, to reconcile this explanation either with the sequence of styles in stratified deposits at Sparta, the most purely Dorian state in historic Greece, or with the geographical distribution of more or less geometrical styles in the South Agean, or (most significant of all) with the very early and emphatic outbreak of geometrical art in Attica and its neighbourhood, which traditionally had been the refuge and rallying ground of nonDorian and pre-Dorian elements from all parts of the invaded area. That the colonies propagated

No. 3096, VoL. 123] 
overseas by these 'Ionian' refugees in conjunction with inhabitants of Attica itself did not share in that geometrical outbreak, is explained if it occurred after their founders had left Attica; and this is in accord with the contrast between Ionian and Attic types of safety-pin, and other elements of culture, and the similarities between Attic safetypins and those of other districts where geometrical styles were established more or less effectively. Provisionally, therefore, the geometrical style may be regarded as an indigenous and local creation of that area of east central Greece where the disturbance and intermixture of older elements in the population seems to have been most intense ; and as the artistic expression of the view of life enforced by the stresses of that crisis.

Characteristic of all geometrical art is the abstract quality of its ornaments : they represent no longer, nor even symbolise, any natural object, but have value through their mere forms or the relation which these forms bear to other forms which comprise them. Frequently an ornament and its background counterchange their functions; and secondary patterns emerge, such as the 'key-fret' and 'wave-coil,' wherein it cannot be said that there is neither design nor background, but only a positive and a negative element-for example, a black and a white-the combination of which is the pattern. In this aspect the Greek geometrical style was not so much a tradition as an invention; the first self-conscious, rationalist style in the history of art. The mere surface of the object, at the frontier between being and not-being, plenum and void-the form of the object, in complete abstraction from-its substance-becomes itself the subject of artistic treatment; anticipating, and perhaps preparing the way for, the philosophical treatment of the same antithesis between form and substance.

A second characteristic is the rhythmical quality of the means employed to distinguish part from whole-the 'many' from the 'one' which they constitute-and attention is directed to the relation between the geometrical art of early Greek craftsmen-including the temple-architects-and the metrical inventions of epic and lyric poetry, the only other aspects of the higher life of that age which have been preserved.

Thirdly, the geometrical experiments in composition and artistic structure in two dimensions (whereas the frieze compositions of the Near East and Asiatic Greece, however elaborate, were essentially in linear series) initiates the progress of Attic and Argive schools of design, of architecture, and eventually of sculpture towards the ideals so nearly attained in the sixth and fifth century: to types of literary compositions best illustrated by Attic tragedians and the fifth century historians; and to remarkable experiments in political recon. struction of certain Greek city-states, and philosophical analysis of the structure of society and of Nature itself.

\section{An Epic of Fastness.}

$\mathrm{M}^{\mathrm{B}}$ R. JAMES MORTON is an artist, an enthusiast, and a man of imagination, and yet he has chosen to be a textile manufacturer. With such a combination of qualities, there is little wonder that within scarcely more than two decades he has been responsible for an amazing change in the standard of colour fastness as applied to woven fabrics. More than to any other man do we owe it to him that to-day the colours of our fabrics are as sound and as permanent as the fibres of which they are made. The story of this development and that of the necessary dyes is unfolded in simple and almost poetic language in a paper read recently before the Royal Society of Arts ${ }^{1}$; it is one which should be read by every student of the present generation as worthy of ranking with similar stories of the great achievements of inventive industry in the past.

It was in 1902 that Mr. Morton, whose firm were makers of high-class furnishing fabrics, was impressed by the fugitive nature of the colours used, and in consequence was led to make exhaustive fading tests on coloured textiles from every source. The uniformly adverse result of these was staggering. It led Morton to institute a constructive campaign which has definitely left a permanent impression on the textile trade of the world. The scheme was to arrive at a range of colours, however small, from which fabrics could be prepared and

History of the Development of Fast Dyeing and Dyes. A paper
read before the Royal Society of Arts on Wednesday, Feb. 20 . No. 3096, VoL. 123] guaranteed against fading from sunlight or ordinary washing. These, under the descriptive name of 'Sundour' fabrics, were first distributed by Messre. Liberty in 1904. The early palette had a modest range of colours; it was greatly helped by the discovery in Germany of the first of the indanthrene vat colours about this time, whilst, in turn, the scope for these vat dyes was greatly increased by the market which the 'Sundour' fabrics had helped to create for them.

By 1914 the fadeless fabric business was firmly established with a world-wide reputation, when on the outbreak of War the manufacturers found themselves suddenly deprived of the supply of German dyes. How Morton first visited other dyemaking concerns to learn their intentions in regard to the vat colours, and how he eventually set to work to make indanthrene blue and yellow for himself, must be read in the original paper. Such dauntless energy as he displayed was bound to succeed, particularly when coupled with a full and proper appreciation of scientific research. Next followed the manufacture of Solway Blue - the fastest of the acid wool colours-and then in 1919 Morton returned from having established his dye processes in America with the British rights of the air oxidation process for the manufacture of phthalic anhydride from naphthalene. He tells how his chemists did not at first value this, but that during the slump in 1920 and 1921, following the Sankey judgment which so nearly destroyed the infant dye 